\title{
PENGARUH KOLOM PASIR TERHADAP PENINGKATAN DAYA DUKUNG TANAH LEMPUNG
}

\author{
Winda Krisdayanti Purba ${ }^{1}$, Suradji Gandi ${ }^{2}$ dan Mohammad Ikhwan Yani ${ }^{3}$ \\ ${ }^{123}$ Program Studi Teknik Sipil, Fakultas Teknik, Universitas Palangka Raya, \\ E-mail: windakrisdayantipurba@gmail.com¹, \\ suradjigandi_ir@jts.upr.ac.id ${ }^{2}$, dan \\ m.ikhwanyani@eng.upr.ac.id ${ }^{3 / H P .+6287848698050}{ }^{1}$
}

\begin{abstract}
ABSTRAK
Tanah lempung memiliki sifat fisik dan mekanis yang khusus, yang mengakibatkan daya dukung tanah menjadi rendah. Penelitian ini bertujuan untuk mengetahui perbandingan hasil pengujian tanah lempung asli dengan yang diberi kolom pasir dalam meningkatkan daya dukung tanah. Berdasarkan pengujian sifat-sifat fisik tanah asli, menurut sistem USCS tanah diklasifikasikan dalam kelompok CL atau lempung anorganik dengan plastisitas rendah sampai dengan sedang, lempung berkerikil, lempung berpasir, lempung berlanau, lempung "kurus" (lean clays). Berdasarkan pengujian kuat geser langsung (Direct Shear Test), tanah lempung dengan kolom pasir $\varnothing 1 \mathrm{~cm}$ mengalami peningkatan sudut geser $(\varphi)$ sebesar 8,283 $\mathrm{kg} / \mathrm{cm}^{2}$ dengan persentase $22,21 \%$ dari tanah asli. Dan pada tanah lempung dengan kolom pasir $\varnothing 1,5 \mathrm{~cm}$ mengalami peningkatan sudut geser $(\varphi)$ sebesar $8,532 \mathrm{~kg} / \mathrm{cm}^{2}$ dengan persentase $22,72 \%$ dari tanah asli. Berdasarkan perhitungan daya dukung tanah lempung menurut Terzaghi, tanah lempung dengan kolom pasir $\varnothing 1 \mathrm{~cm}$ mengalami peningkatan nilai daya dukung tanah sebesar $16,872 \mathrm{~kg} / \mathrm{cm}^{2}$ dengan persentase $57,27 \%$ dari tanah asli. Dan pada tanah lempung dengan kolom pasir $\varnothing 1,5 \mathrm{~cm}$ mengalami peningkatan nilai daya dukung sebesar $19,202 \mathrm{~kg} / \mathrm{cm}^{2}$ dengan persentase $60,404 \%$ dari tanah asli. Berdasarkan hasil penelitian, diameter kolom pasir yang paling efektif terhadap peningkatan nilai daya dukung tanah adalah $\varnothing 1,5$ $\mathrm{cm}$, dimana terjadi peningkatan nilai daya dukung dari tanah asli sebesar 19,202 $\mathrm{kg} / \mathrm{cm}^{2}$ dengan persentase $60,404 \%$.
\end{abstract}

Kata kunci: Kolom Pasir, Tanah Lempung, Pasir, Uji Geser Langsung, Daya Dukung Tanah.

\begin{abstract}
Clay soils have special physical and mechanical properties, which result in low soil bearing capacity. This study aims to determine the comparison between the original clay soil test results and those given a sand column in increasing the bearing capacity of the soil. Based on testing the physical properties of the original soil, according to the USCS system the soil is classified into CL group or inorganic clays with low to moderate plasticity, gravel clay, sandy loam, silty clay, "lean" clays. Based on the direct shear test, clay soil with a sand column of $\emptyset 1 \mathrm{~cm}$ experienced an increase in shear angle $(\varphi)$ of $8.283 \mathrm{~kg} / \mathrm{cm} 2$ with a percentage of $22.21 \%$ of the original soil. And on loam soil with $\varnothing 1.5 \mathrm{~cm}$ sand column, the shear angle $(\varphi)$ increased by $8.532 \mathrm{~kg} / \mathrm{cm} 2$ with a percentage of $22.72 \%$ from the original soil. Based on the calculation of the carrying capacity of clay according to Terzaghi, clay soil with a sand column of $\emptyset 1 \mathrm{~cm}$ has an increase in the value of the carrying capacity of the soil by $16.872 \mathrm{~kg} / \mathrm{cm} 2$ with a percentage of $57.27 \%$ of the original
\end{abstract}


soil. And on clay soil with $\emptyset 1.5 \mathrm{~cm}$ sand column, the bearing capacity value increased by $19.202 \mathrm{~kg} / \mathrm{cm} 2$ with a percentage of $60.404 \%$ from the original soil. Based on the results of the study, the diameter of the sand column which was the most effective in increasing the value of the soil bearing capacity was $\varnothing 1.5 \mathrm{~cm}$, where there was an increase in the carrying capacity of the original soil by 19.202 $\mathrm{kg} / \mathrm{cm} 2$ with a percentage of $60.404 \%$.

Keywords: Sand Column, Clay, Sand, Direct Shear Test, Soil Bearing Capacity.

\section{PENDAHULUAN}

\section{Latar Belakang}

Tanah merupakan komponen penting yang menjadi tempat bertumpunya suatu konstruksi bangunan. Bangunan sangat rentan terhadap kerusakan yang salah satunya disebabkan oleh kondisi tanah yang tidak baik. Setelah melakukan observasi lapangan di Kelurahan Tumbang Rungan Palangka Raya, Kalimantan Tengah, diketahui bahwa kondisi tanah di sekitar lokasi tersebut didominasi oleh tanah lempung. Tanah lempung memiliki sifat fisik dan mekanis yang khusus, diantaranya kadar air yang tinggi, angka pori yang besar, berat volume yang kecil, plastisitas indeks yang besar, sehingga mengakibatkan daya dukung tanah lempung lunak menjadi rendah dan pemampatan yang besar. Hal ini juga menyebabkan sering terjadinya permasalahan yang berdampak pada kegagalan pondasi, kegagalan stabilitas tahanan galian, dan timbunan. Oleh sebab itu harus dilakukan usaha untuk mengatasi tanah yang tidak baik agar dapat digunakan sebagai tanah dasar untuk meletakkan konstruksi bangunan di atasnya dan tidak mengakibatkan kerusakan pada bangunan tersebut. Salah satu metode yang dilakukan dalam usaha perbaikan tanah adalah dengan menggunakan pasir sebagai material kolom pasir yang dipadatkan dan dimasukkan ke dalam lubang pada tanah untuk mengetahui porsi daya dukung tanah tersebut. Dengan mempertimbangkan biaya perkuatan yang relatif mahal, maka sangat perlu untuk dicoba alternatif lain yang lebih murah misalnya penggunaan pasir sebagai perkuatan tanah lunak. Pasir adalah salah satu jenis material yang mudah diperoleh dan harganya pun relatif murah. Pasir juga bersifat keras sedangkan lempung bersifat lunak. Sehingga diharapkan pasir yang dipadatkan sebagai kolom pada tanah lempung dapat menahan beban tekanan lebih besar dari tanah lempung tanpa kolom pasir.

\section{Tujuan Penelitian}

Penelitian ini bertujuan:

1. Mengetahui sifat fisik tanah lempung di daerah Kelurahan Tumbang Rungan Kota Palangka Raya, Kalimantan Tengah.

2. Mengetahui peningkatan nilai daya dukung tanah lempung asli dengan yang diberi kolom pasir melalui pengujian uji geser langsung (Direct shear test).

3. Mengetahui pengaruh kolom pasir terhadap peningkatan nilai daya dukung tanah lempung.

\section{TINJAUAN PUSTAKA}

\section{Tanah Lempung}

Tanah lempung merupakan agregat partikel-partikel berukuran mikroskopik dan submikroskopik yang berasal dari pembusukan kimiawi unsur-unsur penyusun 
batuan, dan bersifat platis dalam selang kadar air sedang sampai luas. Dalam keadaan kering dia akan bersifat keras, jika basah akan bersifat lunak plastis dan kohesif, mengembang dan menyusut dengan cepat, sehingga mempunyai perubahan volume yang besar dan itu terjadi karena pengaruh air.

\section{Pasir}

Pasir adalah partikel batuan yang berukuran $0,074 \mathrm{~mm}$ sampai dengan $5 \mathrm{~mm}$ berkisar dari kasar (3 mm sampai $5 \mathrm{~mm})$ dan halus $(<1 \mathrm{~mm})$ (Joseph E. Bowies, 1984). Pasir dapat dibagi lagi menjadi fraksi-fraksi kasar, medium, dan halus. Pasir dapat di deskripsikan sebagai yang bergradasi baik, bergradasi buruk, bergradasi seragam atau bergradasi timpang (gap graded). (R. F. Craig dan Budi Susilo S, 1987).

\section{Klasifikasi Tanah}

Klasifikasi tanah secara umum adalah pengelompokkan berbagai jenis tanah ke dalam kelompok yang sesuai dengan sifat teknik dan karakteristiknya.

\section{Sistem Klasifikasi AASHTO (AASHTO classification system)}

Sistem ini membagi tanah ke dalam 7 kelompok utama yaitu A-1 sampai dengan A-7. Tanah yang diklasifikasikan ke dalam A-1, A-2, dan A-3 adalah tanah berbutir di mana 35\% atau kurang dari jumlah butiran tanah tersebut lolos ayakan No. 200. Tanah di mana lebih dari 35\% butirannya tanah lolos ayakan No. 200 diklasifikasikan ke dalam kelompok A-4, A-5 A-6, dan A-7. Butiran dalam kelompok A-4 sampai dengan A-7 tersebut sebagian besar adalah lanau dan lempung.

Tabel 1. Klasifikasi Tanah Sistem AASHTO

\begin{tabular}{|c|c|c|c|c|c|c|c|c|c|c|c|}
\hline \multirow{3}{*}{$\begin{array}{l}\text { Klasifikasi Umum } \\
\text { Klasifikasi Kelompok }\end{array}$} & \multicolumn{7}{|c|}{$\begin{array}{c}\text { Tanah berbutir } \\
(35 \% \text { atau kurang dari seluruh contoh tanah } \\
\text { lolos ayakan No. 200) }\end{array}$} & \multicolumn{4}{|c|}{$\begin{array}{c}\text { Tanah lanau - lempung } \\
\text { (lebih dari 35\% dari seluruh contoh } \\
\text { tanah lolos ayakan No. 200) }\end{array}$} \\
\hline & \multicolumn{2}{|c|}{ A-1 } & \multirow{2}{*}{ A-3 } & \multicolumn{4}{|c|}{ A-2 } & \multirow{2}{*}{$A-4$} & \multirow{2}{*}{ A-5 } & \multirow[b]{2}{*}{$A-6$} & \multirow{2}{*}{$\begin{array}{c}\mathrm{A}-7 \\
\mathrm{~A}-7-5^{*} \\
\mathrm{~A}-7-6^{* *}\end{array}$} \\
\hline & A-1a & $A-1 b$ & & A-2-4 & A-2-5 & A-2-6 & A-2-7 & & & & \\
\hline \multicolumn{12}{|l|}{$\begin{array}{l}\text { Analisis ayakan } \\
(\% \text { lolos) }\end{array}$} \\
\hline No. 10 & Maks 50 & - & - & - & - & - & - & - & - & - & - \\
\hline No. 40 & Maks 30 & Maks 50 & $\operatorname{Min} 51$ & $\ldots$ & $\ldots$ & - & $\ldots$ & - & - & - & - \\
\hline No. 200 & Maks 15 & Maks 25 & Maks 10 & Maks 35 & Maks 35 & Maks 35 & Maks 35 & $\operatorname{Min} 36$ & $\operatorname{Min} 36$ & $\operatorname{Min} 36$ & $\operatorname{Min} 36$ \\
\hline \multicolumn{12}{|l|}{$\begin{array}{l}\text { Sifat fraksi yang lolos } \\
\text { ayakan No. } 40\end{array}$} \\
\hline Batas Cair (LL) & \multirow{2}{*}{\multicolumn{2}{|c|}{ Maks 6}} & - & Maks 40 & $\operatorname{Min} 41$ & Maks 40 & $\operatorname{Min} 41$ & Maks 40 & $\operatorname{Min} 41$ & Maks 40 & $\operatorname{Min} 41$ \\
\hline Indek Plastisitas (PI) & & & NP & Maks 10 & Maks 10 & Min 11 & Min 11 & Maks 10 & Maks 10 & $\operatorname{Min} 11$ & Min 11 \\
\hline $\begin{array}{l}\text { Tipe material yang } \\
\text { paling dominan }\end{array}$ & \multicolumn{2}{|c|}{$\begin{array}{l}\text { Batu pecah, } \\
\text { kerikil dan pasir }\end{array}$} & $\begin{array}{l}\text { Pasir } \\
\text { halus }\end{array}$ & \multicolumn{4}{|c|}{$\begin{array}{l}\text { Kerikil dan pasir yang berlanau atau } \\
\text { berlempung }\end{array}$} & \multicolumn{2}{|c|}{ Tanah berlanau } & \multicolumn{2}{|c|}{ Tanah berlempung } \\
\hline $\begin{array}{l}\text { Penilaian sebagai } \\
\text { bahan tanah dasar }\end{array}$ & \multicolumn{7}{|c|}{ Baik sekali sampai baik } & \multicolumn{4}{|c|}{ Biasa sampai jelek } \\
\hline
\end{tabular}

Sumber : Das, B.M, 1995

\section{Sistem Klasifikasi Kesatuan Tanah (Unified Soil Classification System)}

Pada Sistem Unified, tanah diklasifikasikan ke dalam tanah berbutir kasar (Kerikil dan Pasir) jika kurang dari 50\% lolos saringan nomor 200, dan sebagai tanah berbutir halus (lanau/lempung) jika lebih dari 50\% lolos saringan nomor 200. Selanjutnya, tanah diklasifikasikan dalam sejumlah kelompok dan sub kelompok yang dapat dilihat pada Tabel 2. 
JURNAL KACAPURI

Tabel 2. Sistem Klasifikasi Tanah USCS

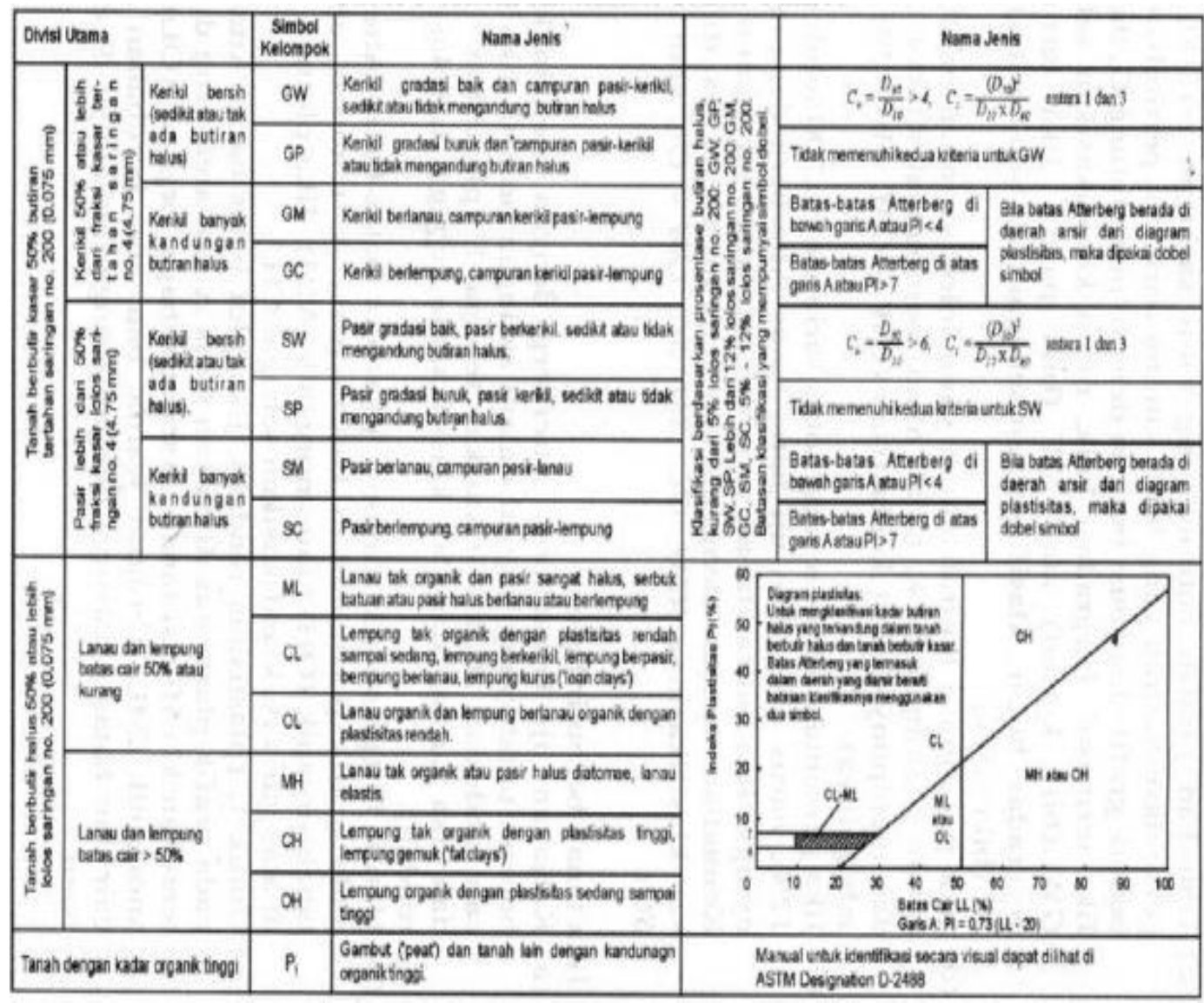

Sumber : Das, B.M, 1995

\section{Kolom Pasir Padat}

Metode kolom pasir ini dilakukan dengan maksud agar pasir yang dipadatkan didorong masuk kedalam lapisan tanah lunak menjadikan suatu kombinasi tanah yang relatif lebih kuat dan padat dari kondisi sebelumnya. Metode ini dilakukan dengan cara memasukkan pasir kedalam pipa-pipa vertikal dalam tanah dan dipadatkan. Dalam hal ini apabila dikenakan beban diatasnya maka kolom-kolom pasir akan lebih dominan dalam memikul beban. Hal ini disebabkan oleh perbedaan karakteristik fisik dan mekanis tiang pasir dan tanah kohesif.

\section{Uji Geser Langsung (Direct Shear Test)}

Uji kuat geser langsung (Direct Shear Test) merupakan cara yang dilakukan di laboratorium untuk mengetahui dan mengukur seberapa kuat tanah menerima gaya geser. Kekuatan geser tanah diperoleh dengan cara menggeser contoh tanah yang diberi beban normal $(\mathrm{N})$ sampai terjadi keruntuhan geser tanah.

\section{Daya Dukung Tanah}

Daya dukung ini merupakan kemampuan tanah untuk mendukung beban dengan asumsi tanah mulai mengalami keruntuhan. Daya dukung tanah ditentukan dari daya dukung ultimate dibagi faktor aman yang sesuai dan dapat dilakukan dengan cara pendekatan empiris untuk memudahkan perhitungannya. Cara perhitungan daya dukung tanah (qu) dapat dihitung dengan menggunakan rumus keruntuhan geser umum pondasi menerus menurut teori Terzaghi: 
$\mathrm{qult}_{\mathrm{ul}} \quad=\mathrm{c} \cdot \mathrm{Nc}+\mathrm{DF} \cdot \gamma \cdot \mathrm{Nq}+0,5 \cdot \gamma \cdot \mathrm{B} \cdot \mathrm{N}_{\gamma}$

Setelah nilai $q_{u}$ didapat, maka nilai daya dukung ijinnya dapat dicari. Daya dukung ijin adalah beban per satuan luas yang diijinkan untuk dibebankan pada tanah di bawah pondasi, agar kemungkinan terjadinya keruntuhan dapat dihindari. Daya dukung ijin dicari dengan rumus:

$q_{a}=\frac{q u}{S F}$

Keterangan :

$q_{a}=$ Daya dukung izin $\left(\mathrm{kg} / \mathrm{cm}^{2}\right)$

$q_{u}=$ Daya dukung batas $\left(\mathrm{kg} / \mathrm{cm}^{2}\right)$

$\mathrm{SF}=$ Faktor keamanan $(1,5-3)$

\section{METODE PENELITIAN}

\section{Lokasi Penelitian}

Penelitian ini menggunakan sampel tanah asli yang berasal dari kawasan Kelurahan Tumbang Rungan Palangka Raya, Kalimantan Tengah dan pasir yang berasal dari Jl. Kalimantan-Buntok Km. 4,6. Studi penelitian ini dilakukan di Laboratorium Mekanika Tanah Jurusan/Program Studi Teknik Sipil Fakultas Teknik Universitas Palangka Raya.

\section{Metode Pengambilan Sampel}

Sampel tanah yang dipakai pada penelitian ini ada dua yaitu sampel tanah asli dan tanah terganggu yang diambil dari kawasan Kelurahan Tumbang Rungan Palangka Raya, Kalimantan Tengah. Contoh tanah asli diambil dengan tabung contoh pada kedalaman tertentu, dan kemudian ditutup rapat, yang bertujuan untuk mencegah pengaruh luar.

\section{Perencanaan Kolom Pasir}

Kolom pasir direncanakan berdasarkan metode coba- coba (trial and error) dengan cara tanah lempung yang selesai di cetak kemudian diberi lubang di tengahnya dengan $\varnothing 1 \mathrm{~cm}$, dan $\varnothing 1,5 \mathrm{~cm}$, setelah itu pasir dimasukkan ke dalam lubang tersebut dan dipadatkan sehingga menjadi kesatuan lalu di keluarkan dari cetakan dan selanjutnya di lakukan pengujian untuk mengetahui sifat mekaniknya dengan menggunakan alat kuat geser dan alat kuat tekan bebas dengan cara pengujian standar. 


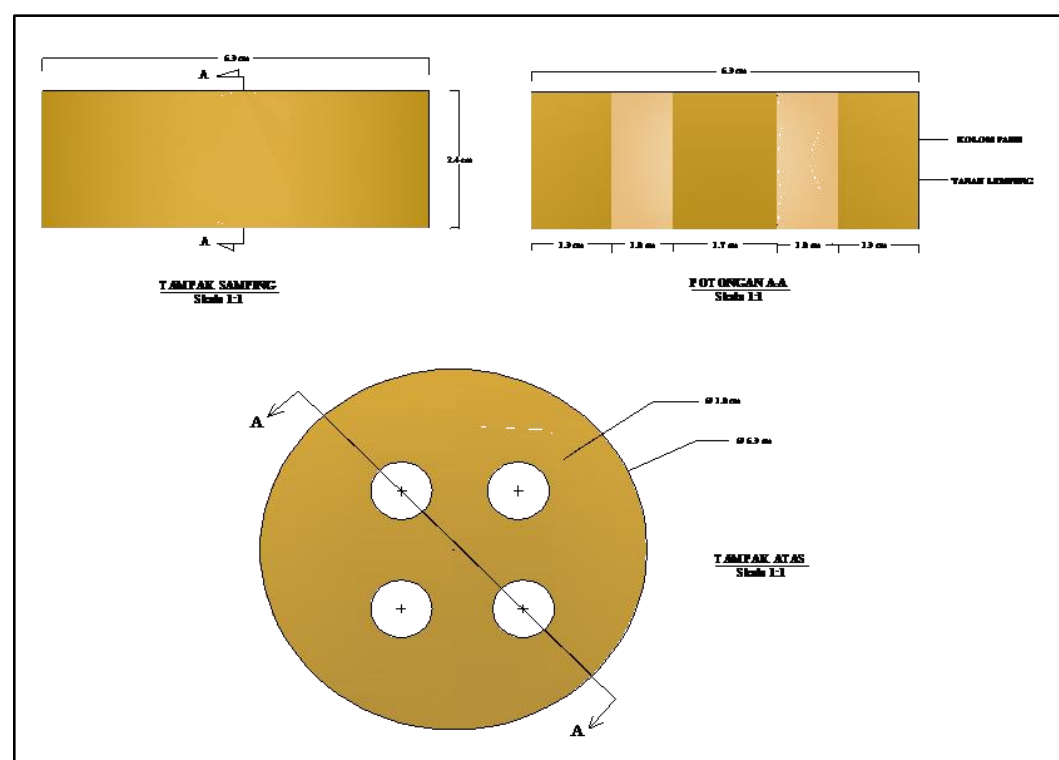

Gambar 1. Perencanaan Pengujian Kuat Geser Langsung Tanah Lempung + Kolom Pasir $\emptyset 1 \mathrm{~cm}$

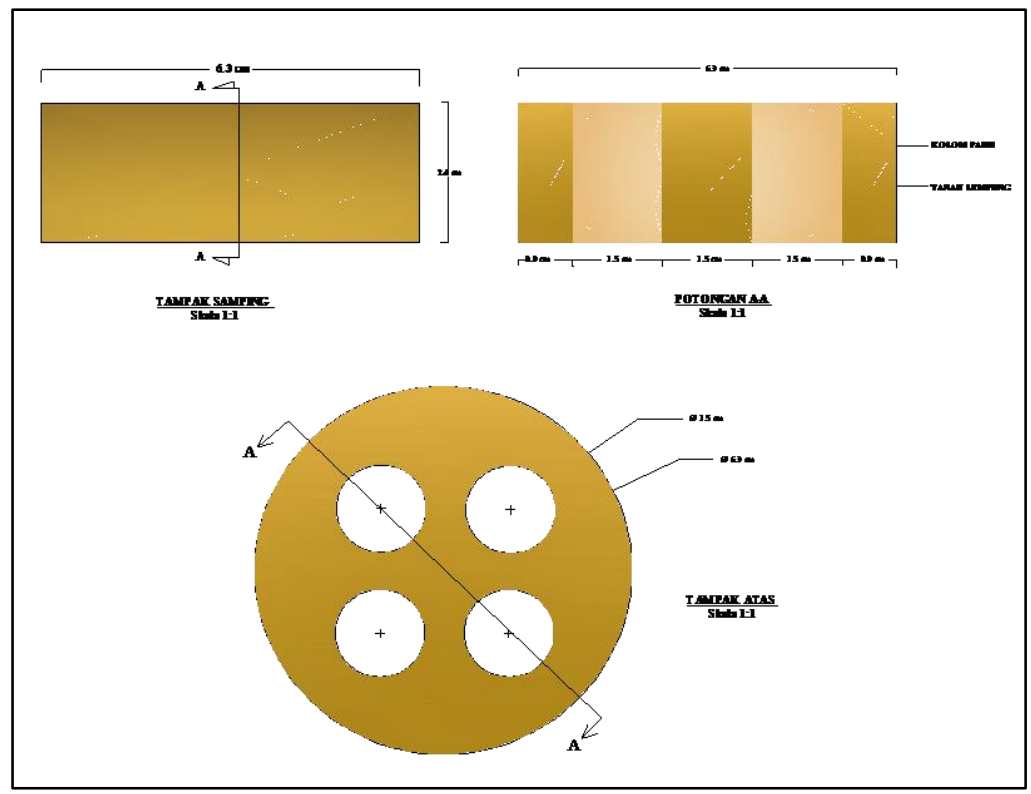

Gambar 2. Perencanaan Pengujian Kuat Geser Langsung Tanah Lempung + Kolom Pasir $\emptyset 1,5 \mathrm{~cm}$

\section{HASIL DAN PEMBAHASAN}

Analisis data dalam penelitian ini dilakukan dengan penggambaran grafik dan perhitungan menggunakan rumus-rumus yang tersedia. Penelitian yang telah dilakukan memperoleh hasil berupa sifat-sifat fisik dan sifat mekanik tanah. 


\section{Hasil Pemeriksaan Sifat-Sifat Fisik Tanah}

Tabel 3. Hasil Pemeriksaan Sifat-Sifat Fisik Tanah

\begin{tabular}{|c|c|c|c|}
\hline No & Jenis Pemeriksaan & Satuan & $\begin{array}{l}\text { Hasil Pemeriksaan } \\
\text { Lempung }\end{array}$ \\
\hline 1. & Kadar Air (w) & $\%$ & 38,16 \\
\hline \multirow[t]{6}{*}{2.} & Berat Volume & & \\
\hline & - $\quad$ Berat Volume Tanah Basah $(\gamma w)$ & $\mathrm{gr} / \mathrm{cm}^{3}$ & 1,83 \\
\hline & - $\quad$ Berat Volume Tanah Kering $(\gamma d)$ & $\mathrm{gr} / \mathrm{cm}^{3}$ & 1,32 \\
\hline & - $\quad$ Angka Pori (e) & $\mathrm{cm}^{3}$ & 1,05 \\
\hline & - Derajat Kejenuhan (S) & $\%$ & 99,72 \\
\hline & - Porositas (n) & & 0,51 \\
\hline 3. & Berat Jenis (Gs) & & 2,70 \\
\hline \multirow[t]{5}{*}{4.} & Batas-batas Atterberg & & \\
\hline & - $\quad$ Batas Cair (LL) & $\%$ & 42,99 \\
\hline & - $\quad$ Batas Plastis (PL) & $\%$ & 23,48 \\
\hline & - $\quad$ Batas Susut (SL) & $\%$ & 13,73 \\
\hline & - $\quad$ Indeks Plastisitas (PI) & $\%$ & 19,51 \\
\hline \multirow[t]{3}{*}{5.} & Analisa Saringan & & \\
\hline & $\begin{array}{l}\text { - Berat tertahan di saringan } \\
\text { No. } 200\end{array}$ & $\%$ & 48,48 \\
\hline & - $\quad$ Lolos saringan No.200 & $\%$ & 51,52 \\
\hline
\end{tabular}

\section{Klasifikasi Tanah}

\section{Klasifikasi Tanah Untuk Jenis Tanah Asli}

Berdasarkan pengujian sifat fisik tanah asli, menurut AASHTO tanah diklasifikasikan dalam kelompok A-7-5 (7) atau tanah berlempung biasa dan menurut sistem USCS tanah diklasifikasikan dalam kelompok CL atau lempung anorganik dengan plastisitas rendah sampai dengan sedang, lempung berkerikil, lempung berpasir, lempung berlanau, lempung "kurus" (lean clays).

\section{Hasil Pemeriksaan Sifat Mekanis Tanah Pemeriksaan Kuat Geser Langsung}

Uji kuat geser langsung (Direct Shear Test) merupakan cara yang dilakukan di laboratorium untuk mengetahui dan mengukur seberapa kuat tanah menerima gaya geser.

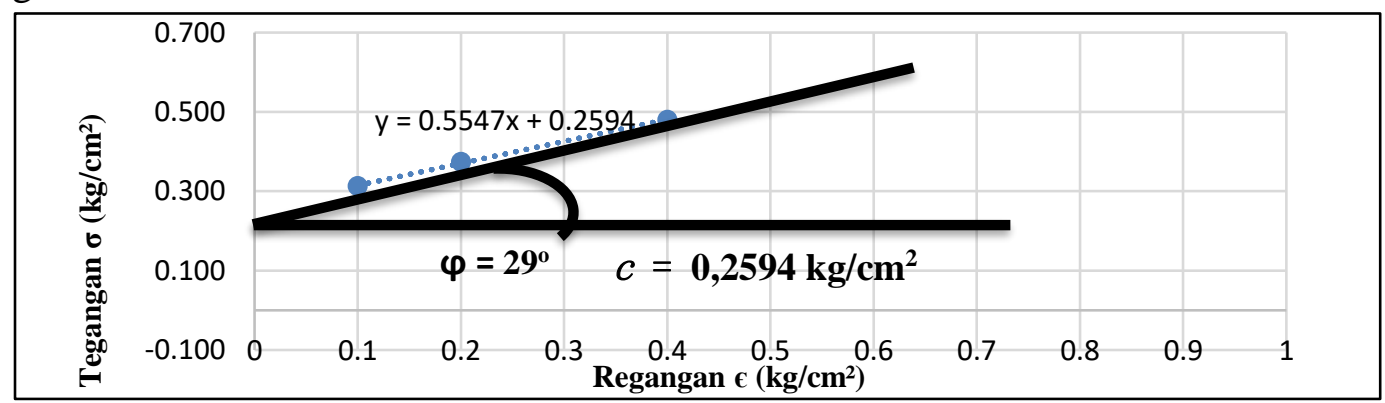

Gambar 3. Grafik Uji Geser Langsung Pada Jenis Tanah Lempung 
Menurut gambar 1. grafik uji geser langsung (Direct Shear Test), sudut geser dalam untuk tanah lempung asli didapat $(\varphi)=\tan ^{-1}(0,5547)=29,017^{\circ}$, dan nilai kohesi $\operatorname{tanah}(\mathrm{c})=0,2594 \mathrm{~kg} / \mathrm{cm}^{2}$.

Tabel 4. Rekapitulasi Hasil Pengujian Uji Geser Langsung

\begin{tabular}{ccc}
\hline Pemeriksaan Jenis Tanah & $(\varphi)^{\mathrm{o}}$ & $\begin{array}{c}(\mathrm{c}) \\
\left(\mathrm{kg} / \mathrm{cm}^{2}\right)\end{array}$ \\
\hline Tanah Asli & 29,017 & 0,2594 \\
Tanah Asli + 4 kolom pasir $\varnothing 1 \mathrm{~cm}$ & 37,300 & 0,2578 \\
Tanah Asli + 4 kolom pasir $\varnothing 1,5 \mathrm{~cm}$ & 37,549 & 0,2380 \\
\hline
\end{tabular}

Berikut diagram nilai sudut geser pada pengujian kuat geser langsung.

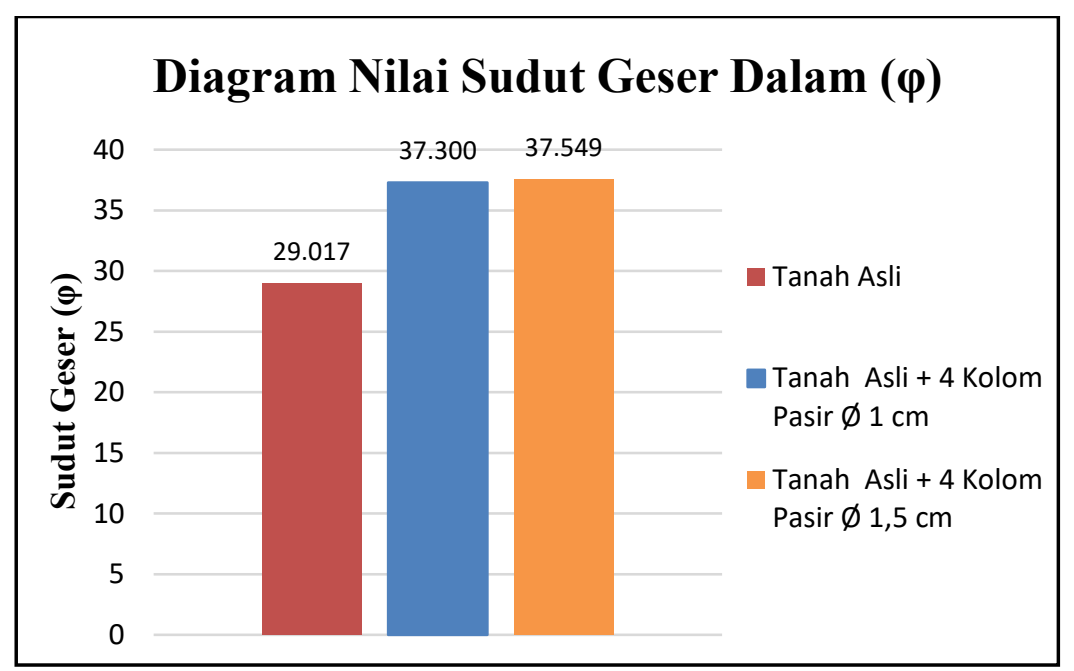

Gambar 4. Diagram Nilai Sudut Geser Dalam $(\varphi)$

\section{Perhitungan Daya Dukung Tanah Menurut Terzaghi (1943)}

Tabel 5. Faktor Daya Dukung Terzaghi Untuk Kondisi Keruntuhan Geser Umum (general shear failure)

\begin{tabular}{|c|c|c|c|}
\hline$\phi$ & $\mathrm{Nc}$ & $\mathrm{Nq}$ & $\mathrm{N} \gamma$ \\
\hline \hline 0 & 5,70 & 1,00 & 0,00 \\
\hline 1 & 6,00 & 1,10 & 0,01 \\
\hline 2 & 6,30 & 1,22 & 0,04 \\
\hline 3 & 6,62 & 1,35 & 0,06 \\
\hline 4 & 6,97 & 1,49 & 0,10 \\
\hline 5 & 7,34 & 1,64 & 0,14 \\
\hline 6 & 7,73 & 1,81 & 0,20 \\
\hline 7 & 8,15 & 2,00 & 0,27 \\
\hline 8 & 8,60 & 2,21 & 0,35 \\
\hline 9 & 9,09 & 2,44 & 0,44 \\
\hline 10 & 9,61 & 2,69 & 0,56 \\
\hline 11 & 10,16 & 2,98 & 0,69 \\
\hline 12 & 10,76 & 3,29 & 0,85 \\
\hline 13 & 11,41 & 3,63 & 1,04 \\
\hline 14 & 12,11 & 4,02 & 1,26 \\
\hline 15 & 12,86 & 4,45 & 1,52 \\
\hline 16 & 13,68 & 4,92 & 1,82 \\
\hline 17 & 14,60 & 5,45 & 2,18 \\
\hline
\end{tabular}

\begin{tabular}{|c|c|c|c|}
\hline$\phi$ & $\mathrm{Nc}$ & $\mathrm{Nq}$ & $\mathrm{N} \gamma$ \\
\hline \hline 26 & 27,09 & 14,21 & 9,84 \\
\hline 27 & 29,24 & 15,90 & 11,60 \\
\hline 28 & 31,61 & 17,81 & 13,70 \\
\hline 29 & 34,24 & 19,98 & 16,18 \\
\hline 30 & 37,16 & 22,46 & 19,13 \\
\hline 31 & 40,41 & 25,28 & 22,65 \\
\hline 32 & 44,04 & 28,52 & 26,87 \\
\hline 33 & 48,09 & 32,23 & 31,94 \\
\hline 34 & 52,64 & 36,50 & 38,04 \\
\hline 35 & 57,75 & 41,44 & 45,41 \\
\hline 36 & 63,53 & 47,16 & 54,36 \\
\hline 37 & 70,01 & 53,80 & 65,27 \\
\hline 38 & 77,50 & 61,55 & 78,61 \\
\hline 39 & 85,97 & 70,61 & 95,03 \\
\hline 40 & 95,66 & 81,27 & 115,31 \\
\hline 41 & 106,81 & 93,85 & 140,51 \\
\hline 42 & 119,67 & 108,75 & 171,99 \\
\hline 43 & 134,58 & 126,50 & 211,56 \\
\hline
\end{tabular}




\begin{tabular}{|l|c|c|c|}
\hline 18 & 15,12 & 6,04 & 2,59 \\
\hline 19 & 16,56 & 6,70 & 3,07 \\
\hline 20 & 17,69 & 7,44 & 3,64 \\
\hline 21 & 18,92 & 8,26 & 4,31 \\
\hline 22 & 20,27 & 9,19 & 5,09 \\
\hline 23 & 21,75 & 10,23 & 6,00 \\
\hline 24 & 23,36 & 11,40 & 7,08 \\
\hline 25 & 25,13 & 12,72 & 8,34 \\
\hline
\end{tabular}

\begin{tabular}{|l|l|l|l|}
\hline 44 & 151,95 & 147,74 & 261,60 \\
\hline 45 & 172,28 & 173,28 & 325,34 \\
\hline 46 & 196,22 & 204,19 & 407,11 \\
\hline 47 & 224,55 & 241,80 & 512,84 \\
\hline 48 & 258,28 & 287,85 & 650,67 \\
\hline 49 & 298,71 & 344,63 & 831,99 \\
\hline 50 & 347,50 & 415,14 & 1072,80 \\
\hline
\end{tabular}

Sumber : Kumbhojkar, (1993)

\section{Daya Dukung Tanah Berdasarkan Hasil Uji Kuat Geser (Direct Shear Test)}

Berdasarkan data hasil pengujian di laboratorium diperoleh:

$(\varphi) \quad=29^{\circ}$, dari tabel 5. didapat nilai $\mathrm{Nc}, \mathrm{Nq}$ dan $\mathrm{N} \gamma$
$\mathrm{Nc}=34,24$
$\mathrm{B} \quad=100 \mathrm{~cm}$
$\mathrm{Nq} \quad=19,98$
Df $\quad=100 \mathrm{~cm}$
$\mathrm{N} \gamma \quad=16,18$
$\gamma \quad=0,00132 \mathrm{~kg} / \mathrm{cm}^{3}$

Keruntuhan Geser Umum Pondasi Menerus:
$\mathrm{q}_{\mathrm{ult}} \quad=\mathrm{c} \cdot \mathrm{Nc}+\mathrm{DF} \cdot \gamma \cdot \mathrm{Nq}+0,5 \cdot \gamma \cdot \mathrm{B} \cdot \mathrm{N}_{\gamma}$
$=(0,2594 \times 34,24)+(100 \times 0,00132 \times 19,98)+(0,5 \times 0,00132 \times 100 \times 16,18)$
$=12,587 \mathrm{~kg} / \mathrm{cm}^{2}$

Daya dukung ijin tanah yang berdasarkan nilai faktor keamanan $=3$, jadi didapat nilai $\mathrm{q}_{\mathrm{ijin}}$ :

$$
\begin{aligned}
\mathrm{q}_{\mathrm{ijin}} & =\left(\frac{1}{S F}\right) \times \mathrm{q}_{\mathrm{ult}} \\
& =\left(\frac{1}{3}\right) \times 12,587 \\
& =4,196 \mathrm{~kg} / \mathrm{cm}^{2}
\end{aligned}
$$

Tabel 6. Hasil Perhitungan Daya Dukung Tanah Berdasarkan Uji Geser Langsung

\begin{tabular}{ccc}
\hline Kondisi Contoh Tanah & \multicolumn{2}{c}{$\begin{array}{c}\text { Daya Dukung Tanah Lempung } \\
\text { Daya Dukung } \\
\text { Tanah }\left(\mathrm{qult}_{\mathrm{ul}}\right)\end{array}$} \\
$\begin{array}{c}\text { Daya Dukung Ijin } \\
\left(\mathrm{kg} / \mathrm{cm}^{2}\right)\end{array}$ \\
$\begin{array}{c}\left(\mathrm{q}_{\mathrm{ijin}}\right) \\
\left(\mathrm{kg} / \mathrm{cm}^{2}\right)\end{array}$ \\
\hline Tanah Asli & 12,587 & 4,196 \\
Tanah Asli + 4 Kolom Pasir $\varnothing 1 \mathrm{~cm}$ & 29,459 & 9,820 \\
Tanah Asli + 4 Kolom Pasir $\varnothing 1,5 \mathrm{~cm}$ & 31,789 & 10,596 \\
\hline
\end{tabular}




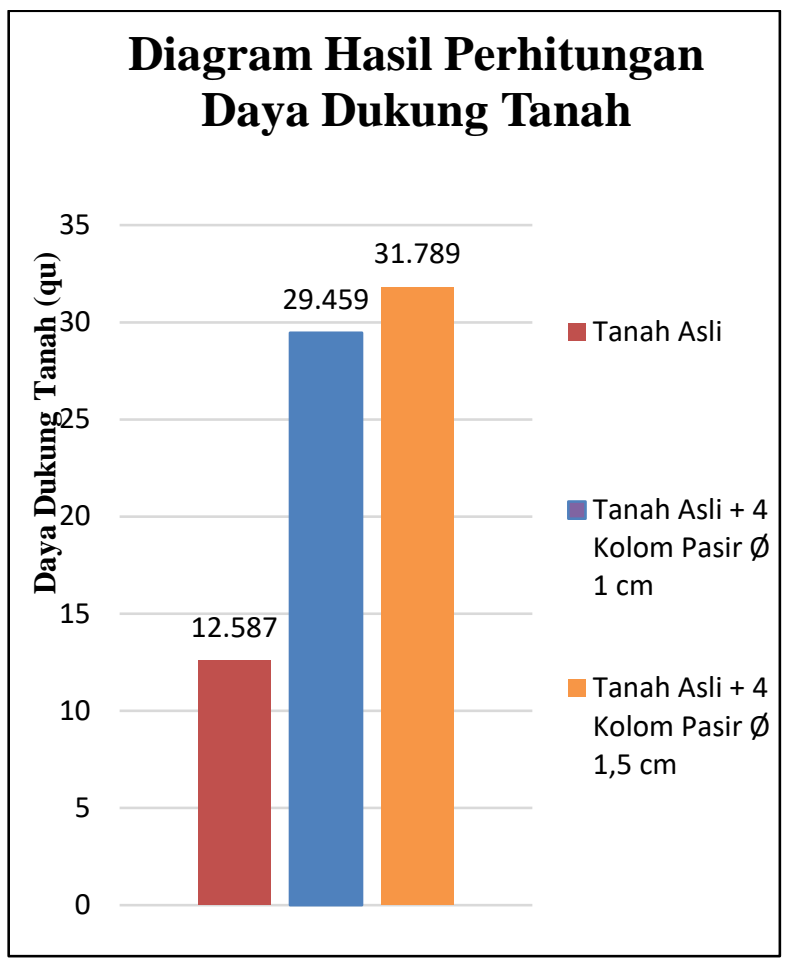

Gambar 5. Diagram Hasil Perhitungan Daya Dukung Tanah

\section{Diagram Hasil Perhitungan Daya Dukung Ijin Tanah}

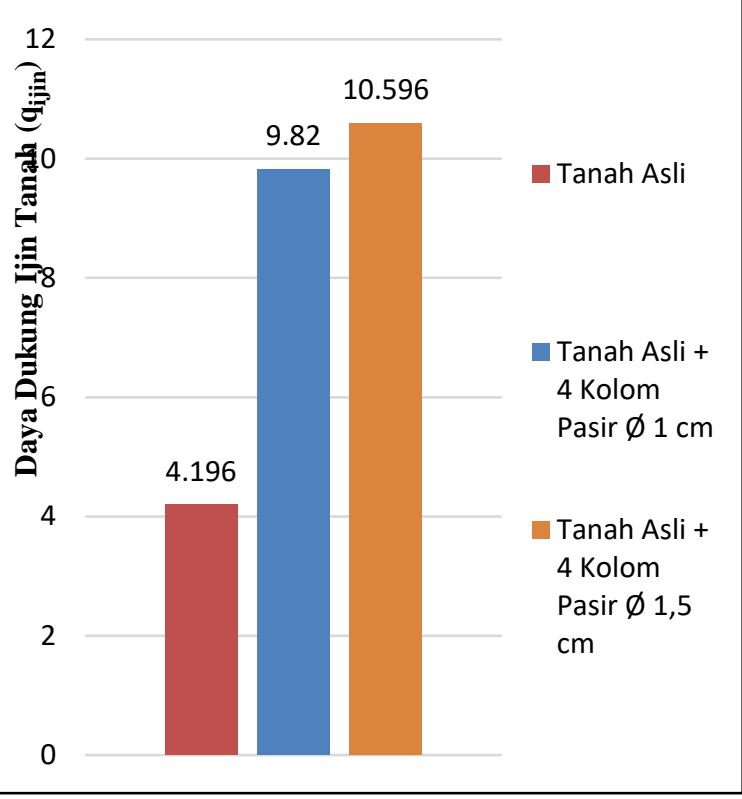

Gambar 6. Diagram Hasil Perhitungan Daya Dukung Ijin Tanah

\section{PENUTUP}

\section{Kesimpulan}

Berdasarkan hasil penelitian dan pembahasan pada bab sebelumnya, maka dapat diambil beberapa kesimpulan sebagai berikut:

1. Tanah yang digunakan pada penelitian ini adalah tanah yang di ambil dari daerah Tumbang Rungan, Kalimantan Tengah. Berdasarkan hasil pengujian diperoleh kadar air $(\mathrm{w})=38,16 \%$. Berat isi $(\gamma)=1,32 \mathrm{gr} / \mathrm{cm}^{3}$. Berat jenis $(\mathrm{Gs})=2,70$. Batas cair $($ Liquid Limit) $=42,99 \%$; Batas Plastis (Plastic Limit) $=23,48 \%$; Indeks Plastisitas $($ Plasticity Index $)=19,51 \%$; Batas Susut $($ Shrinkage Limit $)=13,73 \%$; analisis saringan persentase lolos saringan No.200 $=51,52 \%$ dan nilai $G I=7 \%$. Berdasarkan hasil klasifikasi dengan sistem USCS tanah tersebut masuk ke dalam kelompok CL dan berdasarkan sistem AASTHO tanah tersebut masuk ke dalam kelompok A-7-5 (7) dengan jenis tanah adalah lempung biasa.

2. Berdasarkan pengujian kuat geser langsung (Direct Shear Test), tanah lempung dengan kolom pasir $\varnothing 1 \mathrm{~cm}$ mengalami peningkatan sudut geser $(\varphi)$ sebesar $8,283 \mathrm{~kg} / \mathrm{cm}^{2}$ dengan persentase $22,21 \%$ dari tanah asli. Dan pada tanah lempung dengan kolom pasir $\varnothing 1,5 \mathrm{~cm}$ mengalami peningkatan sudut geser $(\varphi)$ sebesar $8,532 \mathrm{~kg} / \mathrm{cm}^{2}$ dengan persentase $22,72 \%$ dari tanah asli.

3. Berdasarkan perhitungan daya dukung tanah lempung menurut Terzaghi, tanah lempung dengan kolom pasir $\varnothing 1 \mathrm{~cm}$ mengalami peningkatan nilai daya dukung tanah sebesar $16,872 \mathrm{~kg} / \mathrm{cm}^{2}$ dengan persentase $57,27 \%$ dari tanah asli. Dan pada tanah lempung dengan kolom pasir $\emptyset 1,5 \mathrm{~cm}$ mengalami peningkatan nilai daya dukung sebesar $19,202 \mathrm{~kg} / \mathrm{cm}^{2}$ dengan persentase $60,404 \%$ dari tanah asli. Berdasarkan hasil penelitian, diameter kolom pasir yang paling efektif terhadap peningkatan nilai daya dukung tanah adalah $\emptyset 1,5 \mathrm{~cm}$, dimana pada kolom pasir 
$\varnothing 1,5 \mathrm{~cm}$ terjadi peningkatan nilai daya dukung dari tanah asli sebesar 19,202 $\mathrm{kg} / \mathrm{cm}^{2}$ dengan persentase $60,404 \%$.

\section{Saran}

Adapun saran yang dapat diberikan dari penelitian ini adalah:

1. Untuk pengujian sifat fisik dan mekanik tanah diharapkan menggunakan sampel yang tidak terganggu dan dilakukan pengujian secepatnya agar tanah tidak mengeras atau mengering.

2. Diameter kolom pasir harus diperhatikan dan disesuaikan dengan besarnya cetakan untuk masing-masing pengujian, karena besarnya cetakan sangat berpengaruh terhadap besarnya diameter kolom pasir pada saat pembuatan sampel benda uji.

3. Alat uji harus terkalibrasi dengan baik untuk mendapatkan hasil yang akurat.

4. Pemadatan kolom pasir harus dilakukan dengan hati-hati untuk meminimalisir terjadinya retakan pada tanah asli.

5. Perlu dilakukan penelitian lebih lanjut pada jenis-jenis pasir lain yang akan digunakan untuk pengujian kolom pasir.

\section{DAFTAR PUSTAKA}

1. Arif, Syaiful. 2018. Pengaruh Perkuatan Kolom Campuran Pasir-Kapur Terhadap Penurunan Pondasi Telapak Bujur Sangkar. Surakarta: Jurusan Teknik Sipil Fakultas Teknik Universitas Muhammadiyah Surakarta.

2. Bowles, J.E. 1984. Sifat-sifat Fisis dan Geoteknis Tanah. Jakarta: Erlangga.

3. Bowles, J.E. 1988. Analisis dan Desain Pondasi 1. Jakarta: Erlangga.

4. Craig, R. F dan Susilo S. Budi. 1987. Mekanika Tanah. Jakarta: Erlangga.

5. Das, Braja M. 1995. Mekanika Tanah (Prinsip-prinsip Rekayasa Geoteknis) Jilid 1. Jakarta: Erlangga.

6. Hardiyatmo, Hary Christady. 1992. Mekanika Tanah 1. Jakarta: Gramedia Pustaka Utama.

7. Kristanto, Oboy. 2014. Analisa Pengaruh Kolom Pasir Terhadap Peningkatan Daya Dukung Tanah Lempung. Palangka Raya: Jurusan Teknik Sipil Fakultas Teknik Universitas Palangka Raya.

8. Prasenda, Christian. 2015. Pengaruh Penambahan Pasir Terhadap Tingkat Kepadatan Dan Daya Dukung Tanah Lempung Lunak. Lampung: Jurusan

9. Teknik Sipil Fakultas Teknik Universitas Lampung.

10. Terzaghi, Karl dan B. Peck, Raplh. 1967. Mekanika Tanah dalam Praktek Rekayasa Jilid 1. Jakarta: Erlangga.

11. Wesley, L. D. 1977. Mekanika Tanah. Jakarta: Badan Penerbit Pekerjaan Umum.

12. Yani, M. Ikhwan. 2013. Panduan Pratikum Mekanika Tanah 1, Palangka Raya: Fakultas Teknik Universitas Palangka Raya, Palangka Raya.

13. Yani, M. Ikhwan. 2013. Panduan Pratikum Mekanika Tanah 11, Palangka Raya: Fakultas Teknik Universitas Palangka Raya, Palangka Raya. 